\title{
An Empirical Study on the Prediction of Farmers' Ability to Acquire Loans in the Yanliang District Based on Cloud Model
}

\author{
Wang Jing Hu Guangyin Xiang Libin \\ College of Economics and Management, Northwest A\&F University \\ Shanxi, China \\ wj66xyx@126.com,hugy@nwafu.edu.cn,xianglibin1992@163.com

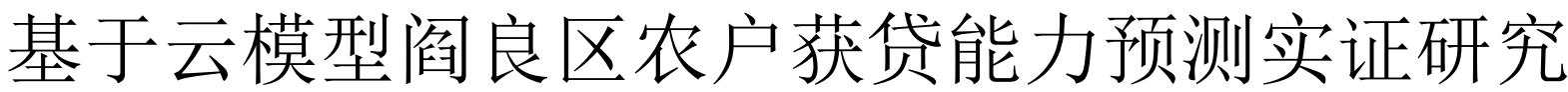 \\ 王静* 胡广银 相立宾 \\ 西北农林科技大学经济管理学院 \\ 陕西 712100, 中国 \\ wj66xyx@126.com,hugy@nwafu.edu.cn,xianglibin1992@163.com
}

\begin{abstract}
Formal lending in rural finance is a powerful way to serve "agriculture, countryside and farmers" and the key to promoting rural economic development. Farmers' demand for funds is expanding day by day. However, there are still some problems caused by information asymmetry in rural financial supply. Through the collation of $\mathbf{2 6 5}$ questionnaires of farmers in Yanliang, Shaanxi Province, and using Logistic model, this paper empirically analyzed the influencing factors of farmers' household characteristics, production characteristics, material capital characteristics and social relations on their loan ability, so as to get the index system of loan forecasting. The cloud model is introduced to solve the fuzziness of some influencing factors. The ability of farmers to obtain loans is divided into five levels. The comparative verification shows that farmers have strong demand for loans but low satisfaction rate, and the financial products of banks need to be improved. At the same time, the model has certain practicability and reliability, which provides a method for farmers' credit qualification evaluation.
\end{abstract}

Keywords-Farmers,rural Loan, Forecasting,Cloud Model

摘要一农村金融中的正规借贷是服务 “三农” 的有力途 径, 是促进农村经济发展的关键, 农户对于资金的需求日益扩 大, 然而农村金融供给还存在着一些信息不对称带来的供需矛 盾。通过对陕西阎良 265 份农户调查问卷的整理, 运用 Logistics 模型, 实证分析了农户家庭特征、生产特征、物质 资本特征、社会关系等对农户贷款能力的影响因素, 以得到获 贷预测的指标体系。引入改进的主客观权重云模型来解决一些 影响因素的模糊性, 将农户的获贷能力分为五个等级, 通过对 比验证显示, 农户借贷需求旺盛但满足率低, 社会资本的无形 抵押作用较大, 社会资本中关系费用、亲密程度和信任程度影 响较大, 银行金融产品有待针对性改善。同时得到该模型具有 一定的实用性和可靠性, 为农户借贷资质评定提供了一个方 法。

\section{I. 引言}

资金和技术是目前制约 “三农” 发展的两大瓶颈, 实现 “农村要发展, 农业要增长, 农民要增收”这一“ 三农” 问题的核心与目标必须解决好这两个关键问题。
然而正规银行机构对农户获得资金的门槛设置偏高, 农 户资金需求一直面临着比较严重的桎梏, 致使有贷款需 求的人选择通过向亲友借款甚至高利贷来满足资金需求 [1-4]。学术界对农户获贷影响因素问题进行了大量研究 , 洪名勇等 [5]、王曙光和王东宾[6]、杨伟坤[7]、彭克强 和刘锡良等 [8]的研究发现户主的文化水平、家庭劳动力 数量、农户对政策的认知、耕地面积、教育和医疗的支 出、社会资本、家庭人口数和平均年龄、农户收入等对 农户借贷行为都有一定程度的影响。孟樱和王静 [9]通过 运用 Logistic 模型研究得出农户的家庭劳动力人数、是否 购买保险以及是否加入合作社对农户的贷款行为有显著 的正向影响。任乐等[10]认为农业保险可被视作一种有效 的抵押品替代信号, 增加农户贷款可得性。李兰兰、赵 岩青[11]、赵岩青、何广文[12]、胡枫[13]认为要利用社 会资本有效降低信贷风险。因此, 研究如何营造便捷快 速高效的借贷环境, 优化农户正规与非正规借贷行为,

从根本上提高有借贷需求的农户从农村金融市场获得借 贷资金的机会, 将是实现农户借贷效率的提升和农业及 农村经济发展的关键环节之一, 也是今后一段时期我国 农村金融改革与政策设计的一个重要目标。

云模型是 1995 年李德毅院士以概率论和模糊数学理 论为理论支撑首先提出的, 其基本原理是把云模型作为 用语言值描述的某个定性概念与其数值表示之间的不确 定性转换模型。崔娟娟[14]、董源[15]、王兆红[16]通过 将云重心的理论引入评价模型, 完成从定性概念与定量 表示间的相互转换, 研究表明将云模型应用于综合预测 是可行的, 且具有广泛的适用性, 本文将云模型引入到 农户信贷能力预测问题上，探讨农户获贷能力评估的方 法, 为缓解小农户与现代农业有机衔接和助力脱贫攻坚 中资金约束瓶颈提出相应的对策方法。

基金项目; 农户生产联结（PPL）机制及其关联性信用风险演化机理研究（71873101)，国家自然科学基金面上项目

作者简介: 王 静 (1966-), 女，陕西汉中人，博士，教授，研究方向：金融工程与农业投资, E-mai1: w j66xyx@126. com; 通讯作者。

胡广银 (1991-), 男, 甘肃白银人, 博士研究生, 研究方向: 农村金融, E-mail: hugy@nwafu. com;

相立宾 (1992-), 男, 河北石家庄人, 硕士研究生, 研究专业: 农业经济管理, E-mai1: xianglibin1992@163.com。 


\section{II. 数据来源与指标选取}

本研究的样本数据来源于西北农林科技大学金融专 业于 2017 年 7 月对陕西省西安市阎良区关山镇、武屯镇 所做的问卷调查。在选定的村进行入户访谈与问卷调 查, 共发放问卷 380 份, 收回 350 份, 本文根据年龄阶 段选取了 25 岁到 60 岁的样本 265 份。本文研究借鉴学 者们的研究并结合实际调研情况, 从农户家庭特征、农 业生产特征、物质资本特征和社会资本这四大方面来衡 量农户的获贷能力, 如表 1 所示。
其中，P 代表农户对金融机构 “有” 获得贷款的概 率， $1-\mathrm{P}$ 代表农户对金融机构 “没有” 获得贷款的概 率, $\beta_{0}$ 为常数项, $X$ 为解释变量, $\beta$ 为回归系数, $\mu$ 为 随机误差项。

建模前首先对自变量进行多重共线性检验, 避免所 选用的自变量不存在严重的多重共线性。

通过使用极大似然法, 采用 Stata 12.0 进行逐步回归 参数估计和检验, 结果如表 2 所示。

表 1 . 变量选取表

\begin{tabular}{|c|c|c|c|c|c|c|}
\hline $\begin{array}{l}\text { 变量类 } \\
\text { 型 }\end{array}$ & 变量名称 & 变量特征及赋值 & 平均值 & 标准差 & 最小值 & 最大值 \\
\hline \multirow{4}{*}{$\begin{array}{l}\text { 家庭特 } \\
\text { 征 }\end{array}$} & 户主年龄（X1） & 取实际值 & 49.9 & 10.86 & 25 & 65 \\
\hline & 受教育程度 $(\mathrm{X} 2)$ & $1=$ 小学及以下, $2=$ 初中, $3=$ 高中 $/$ 中专, $4=$ 大专, $5=$ 本科及以上 & 2.68 & 0.99 & 1 & 5 \\
\hline & 家庭负担比 (X3) & $\mathrm{K}=($ 老人数 + 儿童数 $) /$ 家庭总人数 & 0.45 & 0.28 & 0 & 1 \\
\hline & 家庭经营类型（X4） & $\begin{array}{c}1=\text { 纯农业, } 2=\text { 农业为主, } 3=\text { 界限不清, } \\
4=\text { 非农业为主, } 5=\text { =完全非农业 }\end{array}$ & 2.01 & 1.10 & 1 & 5 \\
\hline \multirow{6}{*}{$\begin{array}{c}\text { 生产特 } \\
\text { 征 }\end{array}$} & 耕地面积（X5） & 取实际值 & 6.47 & 12.53 & 1 & 200 \\
\hline & 作物种类数（X6） & 取实际值 & 1.97 & 0.89 & 1 & 4 \\
\hline & 农业保险（X7） & $1=$ 买农业保险, $2=$ 不买农业保险 & 1.81 & 0.39 & 1 & 2 \\
\hline & 参与合作组织程度 (X8) & $\begin{array}{c}1=\text { 没参与, } 2=\text { 较低参与, } 3=\text { 一般参与, } 4=\text { 较高参与, } 5=\text { 担任重要 } \\
\text { 色 }\end{array}$ & 1.84 & 1.26 & 1 & 5 \\
\hline & 农业补贴（X9） & $1=$ 得到补贴, $2=$ 没有补贴 & 1 & 0.49 & 1 & 2 \\
\hline & 固定资产价值（X10） & $\begin{array}{c}1=5 \text { 万及以下, } 2=5 \text { 万到 } 10 \text { 万, } 3=10 \text { 万到 } 15 \text { 万, } 4=15 \text { 万到 } 20 \text { 万 } \\
\qquad 5=20 \text { 万及以上 }\end{array}$ & 2.24 & 1.11 & 1 & 5 \\
\hline \multirow{5}{*}{$\begin{array}{l}\text { 物质资 } \\
\text { 本特征 }\end{array}$} & 家庭年收入（X11） & 实际值取对数 & 10.50 & 0.91 & 6.40 & 12.15 \\
\hline & 家庭年支出（X12） & 实际值取对数 & 10.28 & 1.06 & 6.91 & 14.68 \\
\hline & 期望贷款数目（X13） & 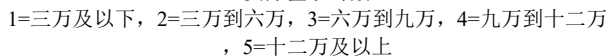 & 2.74 & 1.46 & 1 & 5 \\
\hline & 关系费用（X14） & 实际值取对数 & 8.65 & 0.82 & 6.11 & 11.93 \\
\hline & 家人职业（X15） & $1 、 2 、 3 、 4 、 5$ 表示程度依次变大, 取实际值 & 2.92 & 1.35 & 1 & 5 \\
\hline & 与亲朋频繁程度（X16） & $1 、 2 、 3 、 4 、 5$ 表示程度依次变大, 取实际值 & 3.79 & 0.94 & 1 & 5 \\
\hline \multirow[t]{3}{*}{ 本 } & 与亲朋亲密程度 (X17) & $1 、 2 、 3 、 4 、 5$ 表示程度依次变大, 取实际值 & 3.44 & 0.85 & 1.25 & 5 \\
\hline & 与亲朋互惠程度 (X18) & $1 、 2 、 3 、 4 、 5$ 表示程度依次变大, 取实际值 & 3.47 & 1.01 & 1 & 5 \\
\hline & 与亲朋信任程度 (X19) & $1 、 2 、 3 、 4 、 5$ 表示程度依次变大, 取实际值 & 3.21 & 0.81 & 1 & 5 \\
\hline
\end{tabular}

农户家庭特征（FC），是指家庭成员所拥有的劳动能 力总和, 本文纳入计算的指标包括农户家庭主要劳动力 的年龄、受教育程度、家庭负担比, 家庭负担选择老人 儿童在家庭中的比重。农业生产特征（PC）, 本文主要 计算农户的家庭经营类型、实际耕地面积、作物种类 数、农业保险、参与合作组织程度。物质资本特征 (MC), 包括农户为维持生计所需要的基础设施及其他 固定资产以及家庭金融资本。本文将农户家庭拥有固定 资产状况纳入物质资产指标体系, 具体来说, 包括农户 所拥有的农业机械、家庭耐用消费品（电视机、洗衣 机、缝㧅机、大型家具) 等价值较大的物质资产, 金融 资产是指农户可支配和可筹措的现金，金融资产的作用 体现它能直接弥补农户经济生活中消费和生产的资金空 缺。本文选取的变量主要有农户的年收入、年支出、期 望贷款数额。社会资本 (SC), 社会资产主要表示为实 现发展所需的社会资源, 包括农户自身品质和在生产生 活中形成的社会关系网络。

Logistic 回归模型是根据样本数据采用一系列变量, 根据 ML 法, 得出各参数值, 进而得到相应变量取某个 值时的概率, 从而可预测事件发生的概率。其预测值最 大趋近 1 , 最小值趋近 0 , 一般选择 0.5 作为分割点, 即 如果通过模型计算出来的概率大于 0.5 , 则预测发生, 即 农户获得贷款几率大; 反之则不发生, 即农户对贷款获 得几率低。农户对银行贷款可得性选用二元 Logistic 回 归模型，其公式为:

$$
\ln \frac{P}{1-P}=\beta_{2}+\beta_{2} X_{1}+\beta_{2} X_{2}+\beta_{8} X_{2}+\cdots+\beta_{g} X_{9}+\mu
$$

表 2. 农户回归结果

\begin{tabular}{|c|c|c|c|c|}
\hline & $\begin{array}{l}\text { (1) } \\
\text { 系数 }\end{array}$ & $\begin{array}{l}\text { (2) } \\
\text { 系数 }\end{array}$ & $\begin{array}{l}\text { (3) } \\
\text { 系数 }\end{array}$ & $\begin{array}{l}\text { (4) } \\
\text { 系数 }\end{array}$ \\
\hline 年龄（X1） & 0.0045 & 0.0040 & 0.0077 & 0.0119 \\
\hline 受教育程度（X2） & $0.4993 * * *$ & $0.4600 * * *$ & $0.4147^{* * *}$ & $0.3484 * * *$ \\
\hline 家庭负担比（X3） & $-0.6174^{*}$ & $-0.7735^{* *}$ & $-0.7414 *$ & $-0.6096^{*}$ \\
\hline 家庭经营类型（X4） & & $0.2768 * * *$ & $0.2936^{* * *}$ & $0.2819 * *$ \\
\hline 耕地面积 (X5) & & $-0.0509^{*}$ & $-0.0647 *$ & -0.0499 \\
\hline 作物种类数 (X6) & & $0.4316^{* * *}$ & $0.4181^{* * *}$ & $0.4314^{* * *}$ \\
\hline 农业保险（X7） & & $0.5621^{*}$ & $0.5031^{*}$ & 0.7756 \\
\hline $\begin{array}{c}\text { 是否参与合作社 } \\
\text { (X8) }\end{array}$ & & $0.4974 * * *$ & $0.4469 * * *$ & $0.3774 * * *$ \\
\hline 农业补贴（X9） & & & 0.1799 & 0.1554 \\
\hline 固定资产价值（X10） & & & $0.3055^{* * *}$ & $0.3997 * * *$ \\
\hline 人均年收入 (X11) & & & $0.4090^{* * *}$ & $0.5754 * * *$ \\
\hline 家庭年支出（X12） & & & $-0.2382 * *$ & $-0.2295^{* *}$ \\
\hline 期望贷款数目 (X13) & & & 0.0905 & 0.0816 \\
\hline 关系费用（X14） & & & & $0.3471^{* *}$ \\
\hline 家人职业 (X15) & & & & 0.0553 \\
\hline 频繁程度（X16） & & & & -0.1677 \\
\hline 亲密程度（X17） & & & & $0.4934 * * *$ \\
\hline 互惠程度 (X18) & & & & -0.1116 \\
\hline 信任程度（X19） & & & & $0.3981 * * *$ \\
\hline \multirow[t]{2}{*}{-cons } & - & - & - & - \\
\hline & $3.0976^{* * *}$ & $6.1405 * * *$ & $8.8769^{* * *}$ & $21.3114^{* * *}$ \\
\hline $\mathrm{N}$ & 265 & 265 & 265 & 265 \\
\hline
\end{tabular}

通过对数据的篎选整理和模型回归分析, 我们得到 了对阎良农户获贷能力显著的影响因素, 建立了如表 3 所示的预测指标体系。 
表 3. 农户贷款可得性预测指标体系

\begin{tabular}{|c|c|c|c|}
\hline 目标层 & 一级指标 & 二级指标 & $\begin{array}{l}\text { 指标 } \\
\text { 属性 }\end{array}$ \\
\hline \multirow{9}{*}{$\begin{array}{l}\text { 农户 } \\
\text { 贷款 } \\
\text { 可得 } \\
\text { 性 X }\end{array}$} & $\begin{array}{c}\text { 家庭特征 } \\
\left(X_{1}\right)\end{array}$ & $\begin{array}{l}\text { 受教育程度 }\left(X_{11}\right) \\
\text { 家庭负担比 }\left(X_{12}\right)\end{array}$ & $\begin{array}{l}+ \\
-\end{array}$ \\
\hline & 生产特征 & 家庭经营类型 $\left(X_{31}\right)$ & + \\
\hline & $\left(X_{2}\right)$ & 作物种类数（ $\left.X_{\supset \supset}\right)$ & + \\
\hline & 2 & 参与合作社程度 $\left(X_{33}\right)$ & + \\
\hline & 物质资本 & 固定资产价值（ X $31 ）$ & + \\
\hline & 特征 & 家庭年收入（ $\left.X_{32}\right)$ & + \\
\hline & $\left(X_{3}\right)$ & 家庭年支出（ $X_{33}$ ） & - \\
\hline & 社会资本 & $\begin{array}{c}\text { 关系费用 }\left(X_{41}\right) \\
\text { 与亲朋亲密程度 }\left(X_{12}\right)\end{array}$ & $\begin{array}{l}+ \\
+\end{array}$ \\
\hline & $\left(X_{4}\right)$ & 与亲朋信任程度 $\left(\boldsymbol{X}_{43}\right)$ & + \\
\hline
\end{tabular}

III. 权重的计算

权重是指该指标在整体评价中的相对重要程度, 权 重构成是否合理, 直接影响着预测的科学性。

\section{1.序关系分析法确定主观权重}

序关系分析法与传统主观赋权法的区别是在进行相 邻指标重要程度打分之前, 先对各指标的相对重要性程 度进行排序，整个计算过程具有保序性。

\section{1.指标层对准则层的权重}

评分专家按照以下步骤建立评价指标集 $\left\{\mathrm{x}_{1}\right.$, $\left.\mathrm{x}_{2}, \cdots, \mathrm{x}_{\mathrm{n}}\right\}$ 的序关系: 在 $\left\{\mathrm{x}_{1}, \mathrm{x}_{2}, \cdots, \mathrm{x}_{\mathrm{n}}\right\}$ 中根据评价 准则选择一个他认为最重要的指标, 记为 $\mathrm{y}_{1}$; 经过 $n-1$ 次重复挑选之后, 只剩下一个评价指标, 记为 $\mathrm{y}_{\mathrm{n}}$, 这样 就得到了一个唯一的序关系 $\mathrm{y}_{1}>\mathrm{y}_{2}>\cdots>\mathrm{y}_{\mathrm{n}}$ 。记按照序关系 的相邻指标 $y_{t-1}$ 的权重 $w_{t-1}$ 与 $y_{t}$ 的权重 $w_{t}$ 的比值为 $r_{t}$, 其中 $r_{t}$ 的赋值参考表 4 。

表 4. 赋值参考表

\begin{tabular}{cl}
\hline$r_{t}$ & \multicolumn{1}{c}{ 说明 } \\
\hline 1.0 & 指标 $y_{t-1}$ 与 $y_{t}$ 具有相同程度的重要性 \\
1.2 & 指标 $y_{t-1}$ 比 $y_{t}$ 稍微重要 \\
1.4 & 指标 $y_{t-1}$ 比 $y_{t}$ 明显重要 \\
1.6 & 指标 $y_{t-1}$ 比 $y_{t}$ 强烈重要 \\
1.8 & 指标 $y_{t-1}$ 比 $y_{t}$ 重要 \\
\hline $1.1 、 1.3 、 1.5 、 1.7$ 对应相邻比较判断的中间情况 \\
\hline
\end{tabular}

$$
r_{t}=\frac{W_{t-1}}{W_{t}}(\mathrm{t}=1,2,3 \cdots \mathrm{n})
$$

显然, 对于序关系集 $\left.\left\{y_{1}, y_{2}, \ldots, y_{n}\right\}\right\}_{t}$ 与 $r_{t-1}$ 间必满足

$$
\begin{array}{r}
x_{t-1}>\frac{1}{r_{t}}, \mathrm{t}=2,3,4 \cdots \mathrm{n} \\
\text { 则 } w_{n}=\left(1+\sum_{t=2}^{n} \prod_{t=t}^{n} r_{t}\right)^{-1}
\end{array}
$$

得出 $\mathrm{y}_{\mathrm{n}}$ 的权重后, 根据（1）式可以依次求出 $\mathrm{y}_{\mathrm{n}}$ $1, \cdots, \mathrm{y}_{1}$ 的权重值, 由此可得指标集 $\left\{\mathrm{x}_{1}, \mathrm{x}_{2}, \cdots, \mathrm{x}_{\mathrm{n}}\right\}$ 的权重集 $\left\{\mathrm{W}_{1}, \mathrm{w}_{2} \cdots, \mathrm{w}_{\mathrm{n}}\right\}$ 。

\section{2 指标层对总目标层的权重}

设 $\mathrm{w}_{\mathrm{m}}$ 为第 $\mathrm{m}$ 个准则层下第 $\mathrm{n}$ 个指标对总目标的权重, $\mathrm{w}_{\mathrm{n}}$ 为第 $m$ 个准则层下第 $n$ 个指标对准则层的权重, $w_{m}$ 为第 $m$ 个 准则对总目标的权重, 则: $\mathrm{w}_{\mathrm{mn}}=\mathrm{w}_{\mathrm{m}} \mathrm{W}_{\mathrm{n}}$ 。

2变异系数法确定客观权重
序关系分析法在评价指标权重计算时具有直观易 用、计算量少、保序性好等优势, 但在计算过程中无法 反映指标的数据信息, 影响整体权重结果的科学性, 因 此本文又引入变异系数法来确定客观权重。

变异系数的计算公式如下:

$$
v_{i}=\frac{\sigma_{i}}{\tau_{i}}(1,2, \cdots \mathrm{n})
$$

其中, $v_{i}$ 是第 $\mathrm{i}$ 项指标的变异数, $\sigma_{i}$ 第 $\mathrm{i}$ 项指标的标 准差, $\bar{\gamma}_{i}$ 是第 $\mathrm{i}$ 项指标的平均数。

则各项指标的权重为:

$$
w_{i}=\frac{w_{i}}{\sum_{i=1}^{x} v_{t}}
$$

3主客观权重偏差最小原则的组合权重的确定

设 $w_{t}$ 为第 $t$ 项指标在两种方法下的组合权重, $a_{t}$ 为第 $t$ 项指标在序关系分析法下的权重, $b_{t}$ 为第 $\mathrm{t}$ 项指标在变 异系数法下的权重结果, 将 $\mathrm{w}_{\mathrm{t}}$ 表示为 $\mathrm{a}_{\mathrm{t}}$ 和 $\mathrm{b}_{\mathrm{t}}$ 的线性组合 $(\mathrm{t}=1,2, \cdots \mathrm{n})$, 即:

$$
w_{t}=\alpha \cdot a_{\tau}+(1-\alpha) b_{\varepsilon}
$$

式中 $\boldsymbol{\alpha}$ 表示序关系分析法的权重占组合权重的比 例，(1- $\propto$ ）表示变异系数法的权重占综合权重的比例。

以组合权重与变异系数法权重之间, 以及组合权重 与序关系分析法之间的偏差平方和最小为原则, 建立目 标函数:

$$
\min z=\sum_{i=1}^{n}\left[\left(w_{t}-a_{\tau}\right)^{2}+\left(w_{t}-b_{t}\right)^{2}\right]
$$

将（1）代入（2）得:

$\operatorname{minz}=\sum_{i=1}^{n}\left[\left(\alpha a_{t}+(1-\alpha) b_{t}-a_{t}\right)^{2}+\left(\alpha \cdot a_{t}+(1-\alpha) b_{i}-b_{t}\right)^{2}\right]$

对 (3) 式两边关于 $\alpha$ 求导并令一阶导数等于零, 解 方程得 $\propto=0.5$, 将其带入 (6) 式得 :

$$
w_{t}=0.5 a_{t}+0.5 b_{t}
$$

式 (9) 的推导结果表明: 在主客观权重偏差最小的原 则下, 偏向系数的最优解是 0.5 , 即最合理的权重组合应 该是主客观权重各占 $50 \%$ 。说明主观权重和客观权重对评 价目标有相同的重要性程度。

\section{IV. 云模型建立}

1云模型定义

设 $\mathrm{U}$ 是一个用数值表示的定量论域, $\mathrm{S}$ 是 $\mathrm{U}$ 上的定 性概念, 若定量数值 $x \in U$ U是定性概念 $S$ 的一次随机实 现, $x$ 对 $S$ 的确定度 $\mu(x) \in[0,1]$ 是具有稳定倾向的随机数, 则 $\mathrm{x}$ 在论域 $\mathrm{U}$ 上的分布称为云, 每一个 $\mathrm{x}$ 称为一个云滴

$(\mathrm{x}, \mathrm{H}(\mathrm{x}))$ 。若云滴 $\mathrm{x}$ 满足 $\mathrm{x} \sim \mathrm{N}\left(\mathrm{E}_{N} \mathrm{E}_{n}^{\prime 2}\right), \mathrm{E}_{\mathrm{N}}^{\prime} \sim \mathrm{N}\left(\mathrm{E}_{n} \mathrm{H}_{\mathrm{Q}}^{2}\right)$, 对于定向概念 $\mathrm{S}$ 的确定度满足:

$$
\mu_{e}(\mathrm{x})=\exp \left(-\frac{\left(\mathrm{W} \cdot \mathrm{E}_{n}\right)^{2}}{2 \mathrm{E}_{\frac{2}{2}}^{2}}\right)
$$

则称 $\mathrm{x}$ 在论域 $\mathrm{U}$ 上的分布 $\mathrm{S}\left(\mathrm{E}_{\mathrm{w}}, \mathrm{B}_{n}, \mathrm{H}_{\mathrm{e}}\right)$ 为正态云。

\section{2云模型的数字特征}

云模型通过期望值 $\mathrm{E}_{\mathrm{X}}$ 、熵 $\mathrm{E}_{\mathrm{n}}$ 和超熵 $\mathrm{H}_{\mathrm{e}}$ 这三个特征值 来表达一个语言概念, 简记为 $\mathrm{U}\left(\mathrm{E}_{\mathrm{x}}, \mathrm{B}_{\mathrm{n}}, \mathrm{H}_{\mathrm{e}}\right)$, 其中, $\left[\mathrm{B}_{\mathrm{x}} \pm 3 \mathrm{E}_{\mathbf{n}}\right]$ 是该概念表达的对称作用区域。 
由样本均值可得熵 $E_{n}=\sqrt{\frac{\pi}{2}} * \frac{1}{n} \sum_{i=1}^{n}\left|x_{i}-x\right|$;

3 云的合成

云合成就是将同类别的子云通过综合计算生成一个 新的更深层次的综合云的过程, 设两个子云 $\mathrm{T}_{1}=\left(\mathrm{E}_{\mathrm{x} 1}\right.$, $\left.E_{n 1}, H_{e 1}\right), T_{2}=\left(E_{x 2}, E_{n 2}, H_{e 2}\right), \omega_{1}$ 和 $\omega_{2}$ 为相关权 重, 应用独立正态分布法则, 其综合云为:

$$
\begin{aligned}
& E_{x}=\frac{E_{n 1} E_{n 1}+E_{n 2} E_{n 2}}{E_{n 1}+E_{n 2}} \\
& E_{n}=E_{n 1}+E_{n 2} \\
& H_{e}=\frac{E_{\theta 1} E_{n 1}+E_{e 2} E_{n 2}}{E_{n 1}+E_{n 2}}
\end{aligned}
$$

这是在没有考虑子云权重的情况下, 若每个子云有 一定的权重组成综合云, 例如对于一个语言变量 $T$, 可 以通过 $n$ 个子云定义为： $T\{T 1(E x 1, E n 1, H e 1)$, $\left.\mathrm{T} 2(\mathrm{Ex} 2, \mathrm{En} 2, \mathrm{He} 2), \cdots, \mathrm{Tn}\left(\mathrm{Ex}_{\mathrm{n}}, \mathrm{En}_{\mathrm{n}}, \mathrm{He}_{\mathrm{n}}\right)\right\}$, 且各子 云权重为 $\left\{\mathrm{w}_{1}, \mathrm{w}_{2} \cdots, \mathrm{w}_{\mathrm{n}}\right\}$ 。本文综合云的计算采用的是 虚拟云理论中的浮动云 (floating cloud) 算法, 运算 规则如下:

$E_{X}=\frac{E_{x 1} w_{1}+E_{x 2} w_{2}+\cdots E_{x n} w_{n}}{w_{1}+w_{2}+\cdots w_{n}}$
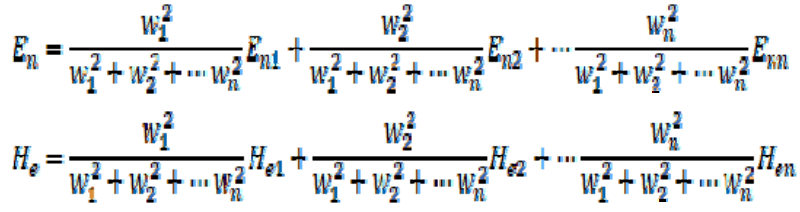

式中: $\omega_{1}$ 是第 $\mathrm{i}$ 个指标的权重; $\left(E_{x i}, E_{n i}, H_{e t}\right)$ 是第 $i$ 个指标的云模型参数; $n$ 为指标的个数。

4 云的距离与云相似度

计算两个云之间的距离:

(1) 通过云发生器将云模型 $\mathrm{T}_{1}=\left(\mathrm{E}_{\mathrm{x} 1}, \mathrm{E}_{\mathrm{n} 1}\right.$, $\left.\mathrm{H}_{\mathrm{e} 1}\right), \mathrm{T}_{2}=\left(\mathrm{E}_{\mathrm{x} 2}, \mathrm{E}_{\mathrm{n} 2}, \mathrm{H}_{\mathrm{e} 2}\right)$ 各生成 $\mathrm{n}$ 个云滴。

(2) 将云滴进行篮选, 删除掉 $\left[\mathbf{E}_{\mathrm{x}}-3 \mathbf{E}_{\mathbf{n}}, \mathbf{E}_{\mathbf{x}},+3 \mathbf{E}_{\mathbf{n}}\right]$ 以外的云滴

(3) 将两个集合 D1 和 D2 按照相对应的顺序计算各 云滴之间的距离, 从而计算出云滴之间的平均距离:

$$
\begin{aligned}
& \mathrm{d}\left(C_{1}, C_{2}\right)=d(D 1, D 2) \\
& =\frac{1}{n_{2}} \sum_{k=1}^{n_{2}} \sqrt{\left.\left(x_{1 k}-x_{2 k}\right)^{2}-\left(\mu(x)_{1 k}\right)-\mu(x)_{2 k}\right)^{2}}
\end{aligned}
$$

（4）基于云距离计算云相似度

$$
\mathrm{s}\left(C_{1}, C_{2}\right)=1-\frac{d\left(C_{1}, C_{2}\right)}{x_{\max }-x_{\min }}
$$

5 评价状态集的确定

隶属云 $\mathrm{CV}$ (Ui) 的确定与评价状态集的评价等级划 分密切相关。根据已有的研究成果, 将农户的贷款可得 性和评价指标属性划分为 5 个评价等级是合适的, 即:

$\mathrm{V}=\{1,2 ， 3 ， 4 ， 5\}=\{$ 高, 较高, 一般, 较低, 低 $\}$
基于黄金分割率的云生成方法, 在论域 $[0,1]$ 范围 内, 以论域中心点 0.5 为 5 个评价等级中的中间评价等 级 “一般” 的期望 $\boldsymbol{E}_{x}$, 越接近论域中心, 评价状态云的 熵 $E_{n}$ 和超熵 $H_{e}$ 越小, 相邻评价状态云的摘 $E_{n}$ 和超熵 $H_{e}$ 的较小者为较大者的 0.618 倍, 则可根据此原理确定评 价状态集中各评价等级的云数字特征及其在 $X$ 轴上的范 围。取中间评价状态 “一般” 的云模型参数为 $E_{x z}=0.5 、 H_{e z}=0.005$, 则各评价状态的云模型参数 如下:

对第 2 个评价状态 “较高”, 参数为:

$$
\begin{aligned}
& \boldsymbol{E}_{n 2}^{*}=E_{n 8}^{n}+\frac{(1-0.618)\left(x_{\min }+X_{n \min }\right)}{2}=0.6 \% 1 \\
& E_{n z}=\frac{(1-0.618)\left(x_{\max }-x_{\min }\right)}{6}=0.064 ; \\
& H_{e 2}=\frac{H_{e 8}}{0.618}=0.0081
\end{aligned}
$$

对第一个评价状态 “高”, 参数为:

$$
E_{w 1}=1, E_{n 1}=\frac{E_{n 2}}{0.618}=0.103 ; H_{\ell 2}=\frac{H_{\ell 2}}{0.618}=0.0131
$$

其余各评价状态的云模型参数可类推。

各评价等级的云数字特征及其在 $\mathrm{x}$ 轴上的范围详见 表 5, 各评价等级对应的评价状态云图见图 1, 其中各评 价等级在 $\mathrm{x}$ 轴上的范围为 $\left[E_{x i}+3 E_{n k}, E_{x i}-3 E_{n i}\right]$, 且在 $[1,0]$ 范围内。

表 5 . 各评价等级的云数字特征

\begin{tabular}{cccccc}
\hline $\begin{array}{c}\text { 可得性 } \\
\text { 等级 }\end{array}$ & 高 & 较高 & 一般 & 较低 & 低 \\
\hline 云模型 & {$[1,0.103$,} & {$[0.691,0.064$,} & {$[0.5,0.031$,} & {$[0.309,0.064$,} & {$[0,0.103$,} \\
& $0.0131]$ & $0.0081]$ & $0.005]$ & $0.0081]$ & $0.0131]$ \\
$\mathrm{X}$ 轴 & & {$[0.883$,} & {$[0.593$,} & {$[0.501$,} & {$[0.309,0]$} \\
范围 & {$[1,0.691]$} & $0.499]$ & $0.407]$ & $0.117]$ & \\
\hline
\end{tabular}

图 1. 各评价等级的状态云图

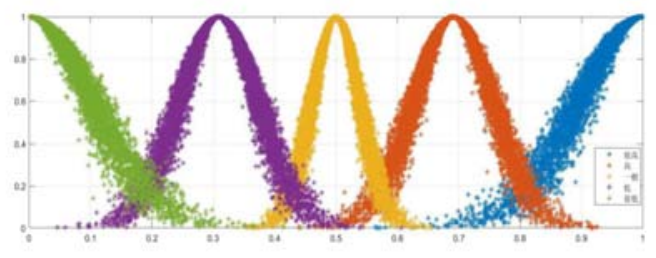

V. 基于云模型的农户获贷可得性预测

\section{1 基于云模型预测的流程}

基于云模型综合评价法是通过云的数字特征描绘出 众多云滴构成的云图, 并借助于云发生器实现定性、定 量信息的转换。建立基于云模型的农户贷款预测模型, 首先要根据贷款可得性的内涵, 分析影响农户贷款的因 素，建立预测指标体系; 然后要确定各个影响因子的权 重; 接下来就是确定评价等级, 本文用黄金分割率模型 驱动法在论域 $[0,1]$ 内, 把可能性分成五个等级: “低”, “较低”, “一般”, “较高”, “高”, 并依次计算各评语云 模型。其次根据云模型转换规则将各评价指标的值转换 成对应的数字特征; 最后做出综合预测。 


\section{2 指标组合权重的计算}

（1）序关系分析法。本文在赋权阶段邀请了 10 位 专家采用邮件的方式来收集一手资料, 其中从事农村金 融方向研究的高校研究人员 5 位, 银行信贷人员 3 人, 农民 2 人。第一步, 对 10 位专家对指标相对重要性排序 的结果进行汇总, 并通过邮件反馈给专家, 通过专家的 反复修改调整, 最终确定统一的序关系集 $y$ 。第二步, 在确定序关系集的基础上, 收集专家对相邻指标的重要 性比值打分结果 $r_{t}$, 共收到 10 份打分结果, 计算每相邻 两项指标重要性比值的均值。第三步, 按照论文 4.2.1 节中的公式 (4-8) 计算排序后组成的序关系集 $y$ 中每项 指标的权重, 按照对应关系来确定指标集 $X$ 中各指标的 权重。一级指标的计算结果如表 6 所示, 二级指标的计 算结果如表 7 所示:

表 6. 一级指标的定序-权值汇总表

\begin{tabular}{cccc}
\hline$y$ & $x$ & $r_{t}$ & 权重 \\
\hline$y_{1}$ & 物质资本特征 $X_{3}$ & 生产特征 $\boldsymbol{X}_{2}$ & 0.310 \\
$y_{2}$ & 生产特征 $x_{2}$ & 1.2 & 0.259 \\
$y_{3}$ & 社会资本 $X_{4}$ & 1.1 & 0.235 \\
$y_{4}$ & 家庭特征 $x_{1}$ & 1.2 & 0.196 \\
\hline
\end{tabular}

表 7.二级指标的定序-权值汇总表

\begin{tabular}{|c|c|c|c|}
\hline$y$ & $x_{1}$ & $r_{t}$ & 权重 \\
\hline$y_{1}$ & 负担比 $X_{12}$ & - & 0.524 \\
\hline$y_{2}$ & 受教育程度 $X_{11}$ & 1.1 & 0.476 \\
\hline$y$ & $x_{2}$ & $r_{t}$ & 权重 \\
\hline$y_{1}$ & 家庭经营类型 $\boldsymbol{X}_{21}$ & - & 0.412 \\
\hline$y_{2}$ & 参与合作社程度 $X_{23}$ & 1.2 & 0.343 \\
\hline$y_{3}$ & 作物种类数 $X_{22}$ & 1.4 & 0.245 \\
\hline$y$ & $x_{3}$ & $r_{t}$ & 权重 \\
\hline$y_{1}$ & 家庭年收入 $X_{32}$ & - & 0.404 \\
\hline$y_{2}$ & 家庭年支出 $X_{33}$ & 1.2 & 0.337 \\
\hline$y_{3}$ & 固定资产价值 $X_{31}$ & 1.3 & 0.259 \\
\hline$y$ & $x_{4}$ & $r_{t}$ & 权重 \\
\hline$y_{1}$ & 与亲朋信任程度 $X_{42}$ & - & 0.383 \\
\hline$y_{2}$ & 与亲朋亲密程度 $X_{43}$ & 1.1 & 0.349 \\
\hline$y_{3}$ & 关系费用 $X_{41}$ & 1.3 & 0.268 \\
\hline
\end{tabular}

（2）基于变异系数法的权重计算

表 8.指标权重-变异系数法

\begin{tabular}{ccccc}
\hline 指标 & 均值 & 标准差 & 变异系数 & 权重 \\
\hline 受教育程度 $\left(\boldsymbol{X}_{11}\right)$ & 2.679 & 0.996 & 0.372 & 0.375 \\
家庭负担比 $\left(\boldsymbol{X}_{12}\right)$ & 0.447 & 0.277 & 0.620 & 0.625 \\
家庭经营类型 $\left(\boldsymbol{X}_{21}\right)$ & 2.011 & 1.104 & 0.549 & 0.325 \\
作物种类数 $\left(\boldsymbol{X}_{22}\right)$ & 1.97 & 0.896 & 0.455 & 0.269 \\
参与合作社程度 $\left(\boldsymbol{X}_{23}\right)$ & 2.014 & 1.378 & 0.684 & 0.405 \\
固定资产价值 $\left(\boldsymbol{X}_{31}\right)$ & 2.242 & 1.115 & 0.497 & 0.314 \\
家庭年收入 $\left(\boldsymbol{X}_{32}\right)$ & 10.501 & 6.248 & 0.595 & 0.375 \\
家庭年支出 $\left(\boldsymbol{X}_{33}\right)$ & 10.276 & 5.059 & 0.492 & 0.311 \\
关系费用 $\left(\boldsymbol{X}_{41}\right)$ & 8.647 & 0.825 & 0.095 & 0.160 \\
与亲朋亲密程度 $\left(\boldsymbol{X}_{42}\right)$ & 3.443 & 0.847 & 0.246 & 0.414 \\
与亲朋信任程度 $\left(\boldsymbol{X}_{43}\right)$ & 3.207 & 0.813 & 0.254 & 0.426 \\
\hline
\end{tabular}

\section{(3) 组合权重的计算}

主观赋权是专家根据实际经验和对实际情况的判断 确定各指标的权重, 是从实际问题出发, 具有一定的实 际意义, 而客观赋权是根据所获得的原始数据确定指标 权重, 确定的权重具客观性, 二者的结果具有同样重要 的意义。

从表 8 可以看出, 通过专家序关系赋权的结果与变 异系数法求得的权重结果有一定的差异。如果运用客观 法确定的权重进行评价可能出现无法解释的结果, 而专 家法得到的权重的值存在较大的随意性, 这对评价结果 的精确性有影响。组合赋权避免二者的缺陷, 使赋权结 果更加客观。本文通过组合权重得到的权重顺序与主观 的序关系法得到的指标权重的重要性顺序相同, 这保证 了所得结果是符合现实情况的，指标组合权重见表 9 。

表 9.指标权重组合

\begin{tabular}{|c|c|c|c|c|c|}
\hline \multirow{2}{*}{ 一级指标 } & \multirow{2}{*}{ 权重 } & \multirow[t]{2}{*}{ 二级指标 } & \multicolumn{2}{|l|}{ 权重 } & \multirow[t]{2}{*}{ 组合权重 } \\
\hline & & & 序关系法 & 变异系数法 & \\
\hline 家庭特征 & \multirow[b]{2}{*}{0.196} & 受教育程度 $\left(X_{11}\right)$ & 0.524 & 0.375 & 0.450 \\
\hline$X_{1}$ & & 家庭负担比 ( $X_{12}$ ) & 0.476 & 0.625 & 0.551 \\
\hline \multirow{3}{*}{$\begin{array}{c}\text { 生产特征 } \\
x_{2}\end{array}$} & \multirow{3}{*}{0.259} & 家庭经营类型 $\left(X_{21}\right)$ & 0.412 & 0.325 & 0.369 \\
\hline & & 作物种类数 $\left(X_{22}\right)$ & 0.343 & 0.269 & 0.306 \\
\hline & & 参与合作社程度 $\left(X_{23}\right)$ & 0.245 & 0.405 & 0.325 \\
\hline \multirow{3}{*}{$\begin{array}{l}\text { 物质资本 } \\
\text { 特征 } X_{3}\end{array}$} & \multirow{3}{*}{0.310} & 固定资产价值 $\left(X_{31}\right)$ & 0.259 & 0.314 & 0.286 \\
\hline & & 家庭年收入 $\left(X_{32}\right)$ & 0.404 & 0.375 & 0.390 \\
\hline & & 家庭年支出 ( $X_{33}$ ) & 0.337 & 0.311 & 0.324 \\
\hline \multirow{3}{*}{$\begin{array}{c}\text { 社会资本 } \\
X_{4}\end{array}$} & \multirow{3}{*}{0.235} & 关系费用 $\left(X_{41}\right)$ & 0.268 & 0.160 & 0.272 \\
\hline & & 与亲朋亲密程度 $\left(X_{42}\right)$ & 0.349 & 0.414 & 0.382 \\
\hline & & 与亲朋信任程度 $\left(X_{43}\right)$ & 0.383 & 0.426 & 0.347 \\
\hline
\end{tabular}

\section{3. 各指标评价云的确定}

首先在分析农户获贷可得性的影响因素基础上, 选 取多个指标建立综合预测指标体系, 对获贷可得性进行 等级划分, 得到指标分级标准; 然后计算不同评价指标 下各等级的云的数字特征, 在 MATLAB 环境下通过编写程 序生成各评价指标不同等级的指标云图, 并根据待评估 农户获贷可得性各指标量化值确定属于不同等级的单指 标确定度; 采用序关系法确定评价指标权值, 通过计算 该农户各指标的综合评价结果, 采用云距离计算该评价 结果与标准云图的相似度, 得到该农户获贷的可能性。

对获贷可得性进行等级划分 (该部分需要说明该等 级划分的原理): 本文将农户的获贷可得性分为很高 $(\mathrm{VH})$ 、高 $(\mathrm{H}) 、$ 一般 $(\mathrm{M})$ 、低 $(\mathrm{L})$ 、很低 $(\mathrm{VL})$ 。各评 价指标的分级标准如表 10 所示。

通过运用一维正向正态云发生器处理农户各指标, 将农户的各指标依据表 5 分别评定为相应等级, 以黄金 分割法模型将其转化为相应云模型。对于这些预测指 标, 由于其之间的相关性较低, 采用虚拟云理论的综合 算法对其进行计算, 将二级指标云模型转化为综合云。

\section{4. 基于云模型的获得可能性预测}

以 $z^{*}=\left(E_{x}^{*}, E_{n}^{*}, H_{e}^{*}\right)$ 为基准, 利用相似度算法将综合云与 基准云进行计算, 相似度越高则其重要度越高, 则其贷 
表 10 .各评价指标分级标准

\begin{tabular}{|c|c|c|c|c|c|c|}
\hline \multirow{2}{*}{ 一级指标 } & \multirow{2}{*}{ 二级指标 } & \multicolumn{5}{|c|}{ 获贷可得性 } \\
\hline & & 很低(VL) & 低(L) & 一般(M) & 高(H) & 很高 $(\mathrm{VH})$ \\
\hline \multirow{2}{*}{ 家庭特征 $X_{1}$} & 受教育程度 ( $X_{11}$ ) & $X_{11}=1$ & $X_{11}=2$ & $X_{11}=3$ & $X_{11}=4$ & $X_{11}=5$ \\
\hline & 家庭负担比 ( $X_{12}$ ) & {$[0.8,1]$} & {$[0.6,0.8)$} & {$[0.4,0.6)$} & {$[0.2,0.4)$} & {$[0,0.2)$} \\
\hline \multirow{3}{*}{ 生产特征 $X_{2}$} & 家庭经营类型 $\left(\boldsymbol{X}_{21}\right)$ & $X_{21}=1$ & $x_{21}=2$ & $x_{21}=3$ & $X_{21}=4$ & $X_{21}=5$ \\
\hline & 作物种类数 ( $X_{22}$ ) & $x_{22}=0$ & $x_{22}=1$ & $x_{22}=2$ & $x_{22}=3$ & $x_{22}=4$ \\
\hline & 参与合作社程度 $\left(X_{23}\right)$ & $x_{23}=1$ & $x_{23}=2$ & $x_{23}=3$ & $x_{23}=4$ & $x_{23}=5$ \\
\hline \multirow{3}{*}{$\begin{array}{c}\text { 物质资本特征 } \\
X_{3}\end{array}$} & 固定资产价值 $\left(X_{31}\right.$ ) & $X_{31}=1$ & $X_{31}=2$ & $X_{31}=3$ & $X_{31}=4$ & $X_{31}=5$ \\
\hline & 家庭年收入 $\left(X_{32}\right)$ & $X_{32}<9.2$ & {$[9.2,10.1)$} & {$[10.1,10.7)$} & {$[10.7,11.2)$} & $X_{32} \geqslant 11.2$ \\
\hline & 家庭年支出 $\left(X_{33}\right)$ & $X_{33} \geqslant 11.4$ & {$[11,11.4)$} & {$[10.2,11)$} & {$[9.5,10.2)$} & $X_{33}<9.5$ \\
\hline \multirow{3}{*}{ 社会资本 $X_{4}$} & 关系费用 $\left(X_{41}\right)$ & $x_{41}<7$ & {$[7,8)$} & {$[8,8.4)$} & {$[8.4,8.8)$} & $x_{41} \geqslant 8.8$ \\
\hline & 与亲朋亲密程度 $\left(X_{42}\right)$ & $X_{42}=1$ & $x_{42}=2$ & $x_{42}=3$ & $X_{42}=4$ & $X_{42}=5$ \\
\hline & 与亲朋信任程度 $\left(X_{43}\right)$ & $X_{43}=1$ & $X_{43}=2$ & $x_{43}=3$ & $X_{43}=4$ & $x_{43}=5$ \\
\hline
\end{tabular}

款可得性越高。利用云模型的相似度算法计算各农户综 合云与基准云的相似度, 进而得到其可得性预测。

以农户 1 为例, 对其进行实例计算。农户 1 年龄 43 岁, 受教育程度为大专, 家庭负担比为 0.22 , 家庭经营 以非农业为主, 家庭年收入 150000 , 年支出 77000 , 农 业仅种植玉米和小麦两种农作物, 与亲戚朋友关系良 好。首先对其各项指标进行云模型综合计算, 其获贷可 得性综合云为: $(0.585,0.057,0.007)$, 获贷可得性为 $52 \%$ 。

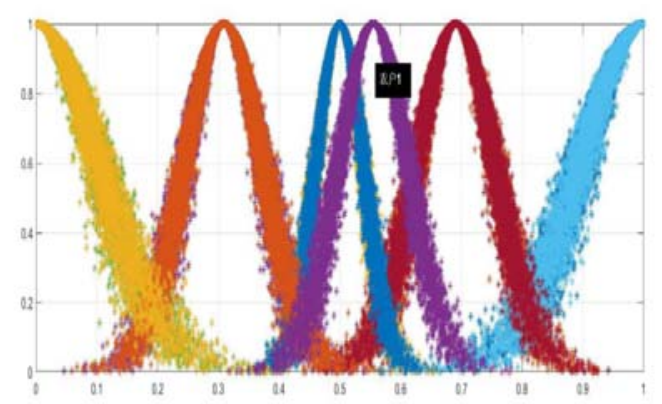

从图中可以看出农户 1 的获贷可得性基于一般和高 之间, 从而得出其获得贷款可能性较高。重复以上步 骤, 可得到各农户的获贷可得性。我们选取了 2018 年阎 良 10 为农户进行了预测, 并采用了结构方程模型方法和 模糊数学模型进行对比, 其结果与本方法基本一致。

\section{VI. 结论}

本文采用云模型对阎良区农户的相关数据进行分 析, 实证结果表明: 物质资本特征在一级指标中权重最 大, 物质资本最能反映出农户的偿贷能力, 其中固定资 产和年收入比重接近, 可见抵押物和财务流水还是处于 重要评估位置上。家庭特征中, 受教育程度反映了农户 对技术进步的接受能力和对市场信息的掌握能力, 具有 显著的正向影响, 家庭负担过大则会减弱农户的获贷能 力。农户的生产特征中家庭经营类型比重较大, 金融机 构还是侧重于盈利潜力, 农业的不确定性增加了贷款风 险, 多种作物类型可以有效降低风险, 经济作物对市场 的参与度更高, 农户获取信息更频繁, 对市场价格的被
动性有所降低。在社会关系中, 维护关系的投入与关系 的稳固性呈正相关, 亲密程度和信任程度对农户获得贷 款具有积极作用, 可见在 “关系” 问题上互惠并不是主 要因素, 这也反映出社会资本的复杂性，亲戚之间可能 并不会因为金钱利益而破坏稳固性, 彼此的信任占据着 主要位置。农村抵押物少, 土地、宅基地等作为抵押物 尚不成熟, 银行在惠农政策下, 更多掌握农户的信息, 将社会资本等因素纳入考量, 势必会有效降低金融风 险, 同时也会增加农户获贷普及率, 达到互利共赢。

\section{致谢}

本研究受国家自然科学基金农户生产联结机制及其 关联性信用风险演化机理研究 (71873101) 资助。

\section{参考文献}

[1] Cheng E, Xu Z. RATES OF INTEREST, CREDIT SUPPLY AND CHINA'S RURAL DEVELOPMENT[J]. Savings \& Development, 2004, 28(2):131-156.

[2] Song X , Li L , Xiao L . Review of Research on Credit Risk Management for Rural Credit Cooperatives[J]. Journal of Risk Analysis \& Crisis Response, 2017, 7(1):21.

[3] 王芳, 罗剑朝. 农户金融需求影响因素及其差异性一一基于 Probit 模型和陕西 286 户农户调查数据的分析 [J]. 西北农林科大学学报, 2012 (06) :61-69.

[4] 张兵, 刘丹, 郑斌. 农村金融发展缓解了农村居民内部收入差距吗? ——基于中国 省级数据的面板门槛回归模型分析 [J].中国农村观察, $2013(03): 19-29$.

[5] 洪名勇, 代则光.农户借贷行为影响因素分析一一基于贵州 5 个县 393 户农户的 调查数据[J].贵州社会科学.贵州社会科学.2012(11):80-83.

[6] 王曙光, 王东宾. 双重二元金融结构、农户信贷需求与农村金融改革——基于 11 省 14县市的田野调查[]]. 财贸经济, 2011(5):38-44.

[7] 杨伟坤, 王立杰, 张永升, 等, 我国农村微型金融发展与创新研究——基于农村微型 金融创新案例分析 [J]. 农业经济, 2012(5):75-77.

[8］彭克强, 刘锡良. 农民增收、正规信贷可得性与非农创业[J]. 管理世界, 2016(7):8897.

[9] 孟贸, 王静. 农户信贷配给情况及影响因素分析[J]. 西北农林科技大学学报(社会科 学版), 2017(3):59-66.

[10] 任乐, 王性玉, 赵辉. 农户信贷可得性和最优贷款额度的理论分析与实证检验一 基于农业保险抵押品替代视角[J]. 管理评论, 2017, 29(6):32-42.

[11] 李兰兰, 赵岩青. 社会资本视角下我国农信社小额信贷运作情况研究 [J]. 财贸经济, 2008(9):34-39.

[12] 赵岩青, 何广文. 声誉机制、信任机制与小额信贷[J]. 金融论坛, 2008, 13(1):33-40.

[13] 胡枫, 陈玉宇. 社会网络与农户借贷行为——来自中国家庭动态跟踪调查(CFPS)的 证据[J]. 金融研究, 2012, (120)(12):178-192.

[14] 崔娟娟, 王英. 江苏省装备制造业产业脆弱性评价指标体系构建及评价研究[J]. 科 技进步与对策, 2015, 32(20):125-131.

[15] 董源. 基于组合赋权-云模型理论的岩爆预测研究 [J]. 地下空间与工程学报, 2018, $14(\mathrm{z} 1)$

[16] 王兆红. 利用云模型预测生鲜类商品的日供应量[J]. 商场现代化, 2006(19):65-65. 